\title{
Use of recommended medications after myocardial infarction in Austria
}

\author{
Wolfgang C. Winkelmayer • Anna E. Bucsics • \\ Alexandra Schautzer · Peter Wieninger · \\ Michaela Pogantsch for the Pharmacoeconomics Advisory \\ Council of the Austrian Sickness Funds
}

Received: 2 July 2007/ Accepted: 7 November 2007 / Published online: 7 December 2007

(C) The Author(s) 2007

\begin{abstract}
Guidelines recommend long-term use of betablockers (BB), statins, and angiotensin-converting-enzymeinhibitors or angiotensin-receptor-blockers (ACEI/ARB) after myocardial infarction (MI), but data on their use after discharge are scarce. From Austrian sickness funds claims, we identified all acute MI patients who were discharged within 30 days and who survived $\geq 120$ days after MI in 2004. We ascertained outpatient use of ACEI/ARBs, BBs, statins, and aspirin from all filled prescriptions between discharge and 120 days post MI. Comorbidities were ascertained from use of indicator drugs during the preceding year. Multivariate
\end{abstract}

Participating Members of the Pharmacoeconomics Advisory Council of the Austrian Sickness Funds (PSF = Provincial Sickness Funds): Karin Eger, MBA; Ursula Griesser, MSc; Cornelia Siess, MD (PSF Vienna); Jana Fischer, PhD; Michaela Stitz, MD (PSF Lower Austria); Berthold Reichardt, MSc (PSF Burgenland); Jürgen Soffried, MD (PSF Upper Austria); Harald Klier, MD; Gerrit Uhl, MSc (PSF Styria); Ursula Riess, MD; Ulrike Wieser, MD (PSF Carinthia); Renato Kasseroller, MD, Michael Prossinger, PhD (PSF Salzburg); Monika Schumlits, MD; Franz Schweinberger, MA (Farmers' Insurance Funds); Beate Preiss, MBA; Andreas Stummer, MD (Federal Employees' Insurance Funds).

W. C. Winkelmayer ( $\square)$

Division of Pharmacoepidemiology and Pharmacoeconomics, Department of Medicine, Brigham and Women's Hospital, Harvard Medical School, 1620 Tremont Street, Suite 3030, Boston, MA 02120, USA

e-mail:wwinkelmayer@partners.org

A. E. Bucsics · P. Wieninger

Hauptverband der Österreichischen Sozialversicherungsträger,

Vienna, Austria

A. Schautzer - M. Pogantsch for the Pharmacoeconomics Advisory

Council of the Austrian Sickness Funds

Steiermärkische Gebietskrankenkasse, Graz, Austria logistic regression was used to evaluate the independent determinants of study drug use. We evaluated 4,105 MI patients, whose mean age was $68.8( \pm 13.2)$ years; $59.5 \%$ were men. Within 120 days after MI, $67 \%$ filled prescriptions for ACE/ARBs, $74 \%$ for BBs, and $67 \%$ for statin. While $41 \%$ received all these classes and $34 \%$ two, $25 \%$ of patients received only one or none of these drugs. Older age and presence of severe mental illness were associated with lower use of all drug classes. Diabetics had greater ACEI/ARB use. Fewer BBs were used in patients with obstructive lung disease. Statin use was lower in patients using treatment for congestive heart failure (all $P<0.001$ ). We conclude that recommended medications were underused in Austrian MI survivors. Quality indicators should be established and interventions be implemented to ensure maximum secondary prevention after MI.

Keywords Myocardial infarction · Statins · Beta-blockers - Angiotensin converting enzyme inhibitors . Angiotensin receptor blockers $\cdot$ Secondary prevention

\section{Introduction}

Cardiovascular disease is among the leading causes of premature death and morbidity in most Western societies. Fortunately, the prognosis of myocardial infarction (MI) has steadily improved over the past decades: case fatality after MI has decreased and long-term survival has increased [1-3], likely due to the introduction and increasing availability and use of acute invasive and non-invasive interventions as well as the introduction of powerful medications for secondary prevention [4].

Among the medications for long-term secondary intervention, aspirin, beta-receptor blockers (BB), 3-hydroxy- 
3-methyl-glutaryl-co-enzyme-A inhibitors (statins), and angiotensin converting enzyme (ACE) inhibitors have drawn the most attention. More recently, angiotensin receptor blockers (ARB) have become available for use in those patients who develop adverse events from ACE inhibitors; ACE inhibitors and ARBs have been shown to be equally efficacious and effective after MI [5-7].

All these interventions are highly efficacious in reducing the recurrence of MI, the subsequent use of coronary interventions, or the risk of death, and have been demonstrated to be highly attractive economic investments from a societal perspective [8-11]. Practice guidelines recommend the use of these medications for secondary prevention in patients with unstable angina or MI, regardless whether the MI is associated with ST-elevation [12-14]. Considerable variation has been observed, however, in the use of these beneficial interventions [3, 15-17], which has prompted the establishment of quality of care indicators in some countries with the goal to monitor appropriate use of these interventions during hospitalization, at discharge, and during outpatient follow-up after such an event [18-20]. Most relevant in the long run, however, is the outpatient use of these medications after discharge from MI. Several studies have indicated that these drugs are underused for secondary prevention. Most of these investigations were conducted in North America [21-23] and in Europe [24-29]. No such systematic assessment has been conducted in the Austrian health care system except for a small local study [30]. We sought to fill this void by studying proportions of BB, statin and ACE inhibitor or ARB use after MI in a large period cross-section of Austrian MI patients.

\section{Methods}

\section{Data sources}

Austria is a social welfare state that mandates universal health care to its residents [31]. Patients are assigned membership in one of several sickness funds dependent on their type and location of current or former employment. At the time covered by this study, there were 20 sickness funds in Austria; among those, the 9 provincial sickness funds covering more than three quarters of all residents (6.2 Mio. of 8.2 Mio. overall; data from 2004). Most inpatient and outpatient medical services are covered and each service encounter generates a claim to the health care system. Inpatient services are not paid directly by sickness funds, but by a separate entity, which, however, is partly funded by these. Thus, sickness funds are also informed about each encountered inpatient care. Similarly to most western health care systems, datasets provided by hospitals contain diagnosis codes, admission and discharge dates. Access to prescription drugs is equal across sickness funds and all medications that are deemed efficacious by a national panel are reimbursed. The copayment for medicines per package was $€ 4.25$ in 2003, €4.35 in 2004 and €4.45 in 2005. Packages of chronic medications usually contain 28,30 , or 50 pills. Sickness fund premiums, other coinsurance and copayments vary slightly, and indigent patients can apply for waiver of the usually modest copayment for prescription drugs. Few medications are subject to prior authorization by the sickness funds. Prescription claims contain a unique identifier for the specific drug, the dose, and the quantity dispensed.

\section{Study population}

For the purpose of this study, we used the complete claims data of individuals covered by several of these sickness funds: the provincial sickness funds (Gebietskrankenkasse) of Vienna, Lower Austria, Upper Austria, Styria, Burgenland, and Carinthia, as well as the funds covering all federal employees (Bundesversicherungsanstalt, BVA) and farmers (Sozialversicherung der Bauern, SVB), respectively. Cumulatively, these sickness funds cover approximately 6.1 million members of the total Austrian insured population of 8.2 million. Each sickness fund separately identified from their insurance claims all patients who were hospitalized and discharged with a primary diagnosis of acute MI in 2004 (International Classification of Diseases, ICD-9: 410.xx; ICD-10: I21) and provided us with their relevant anonymized health care claims data covering the period from January 1, 2003 to June 30, 2005. We only studied each patient's first hospitalization for MI (including direct transfers from one hospital to another) and required that the admission date be between January 1, and December 31, 2004. We retained only those patients whose hospitalization exceeded 3 days and who were admitted at an acute care hospital. Including patients who were hospitalized $<4$ days would open up the possibility of wrongly selecting patients into the study sample who had not experienced an MI (e.g., whose MI was ruled out or patients who were admitted for a diagnostic or therapeutic intervention and still coded for acute MI). Our approach of identifying patients with MI has been validated in similar claims data and found to be highly accurate (positive predictive value: 94\%) [32]. Since we were interested in medication use after MI, we generated a uniform outcomes ascertainment window and required all patients to be discharged within 30 days and to have survived for $\geq 120$ days from their initial admission date (=index date). We also excluded those patients whose hospitalization occurred at a nonacute care hospital. 
Outcomes: use of recommended medications after myocardial infarction

From all filled prescriptions, we recorded out-of-hospital use of several medications between date of discharge and 120 days after MI admission: aspirin, beta-blockers, statins, and ACE inhibitors or ARBs. We also assessed the total number of distinct medications that patients received among statin, BB, and ACE inhibitor/ARB (minimum 0; maximum 3). Since aspirin was available for a price that was below the amount of the drug copayment (€4.35), it is possible that insurance claims data may lead to underascertainment of aspirin use. Thus, we decided to investigate aspirin separately, and only among patients who had their copayment waived based on income grounds. These indigent patients had a clear economic incentive to fill prescriptions for aspirin via the prescription route, thus generating a claim to the sickness fund.

\section{Covariates}

We created variables indicating each patient's age in 2004, gender, the length of stay for their index admission, and whether a patient had their prescription copayments waived during the study period (NoCopay vs. Copay). Since claims from outpatient encounters did not contain any diagnosis codes, we ascertained medication use in the 365 days prior to the index date as proxies for several comorbidities using the anatomic therapeutic chemical (ATC) classification system: oral antidiabetic drugs, insulin, antigout medications, several cardiovascular drug classes (alpha blockers, BBs, calcium channel blockers, ACE inhibitors, ARBs, other antihypertensives, diuretics, nitrates, digitalis, vitamin K-antagonist, statins, fibrates), medications indicated for asthma or chronic obstructive pulmonary disease (COPD; inhaled corticosteroids, beta-receptor agonists), drugs reducing gastro-esophageal reflux or ulcer disease (histamine- $\mathrm{H}_{2}$-blockers, proton pump inhibitors, sucralfate, antacids), pain medications (including non-steroidal anti inflammatory drugs, selective COX-2 inhibitors, opioids, and others), oral corticosteroids, and several psychoactive drug classes (benzodiazepines or anxiolytics, antidepressants, antipsychotics). We also recorded the number of hospital days during the year prior to the index date (categorized into: no hospitalization, 1-7, 8-21, and $>21$ days).

\section{Statistical analysis}

We plotted the unadjusted proportions of medication use for the overall population as well as by copayment status along with the corresponding $95 \%$ confidence intervals (CIs). We then used univariate and multivariate logistic regression to estimate the crude and multivariate adjusted odds of receiving a given study medication. Since none of our outcomes were rare, we were able to create full multivariate models that included all variables regardless of their statistical significance. In large datasets where outcomes are not rare, full multivariate models are superior to parsimonious models, because they provide better control for residual confounding compared to more restricted models. Odds ratios (OR) were presented with their 95\% CIs. Additionally, we showed the population distribution of the number of different study drug classes received among statin, $\mathrm{BB}$, and $\mathrm{ACE}$ inhibitor/ARB (minimum 0; maximum 3). Multivariate ordinal logistic regression and linear regression were used to model the associations between covariates and the number of drugs received. All analyses were conducted in the full final study population as well as after restriction to new users of each study drug, i.e. patients who had not received the respective study drug in the year prior to admission for MI. We used the SAS for Windows (release 9.2) software for all statistical analyses (The SAS Institute, Cary, $\mathrm{NC}$ ).

\section{Results}

\section{Study population}

We first identified 8,416 hospitalizations with a discharge diagnosis indicating an MI. After excluding all repeat MI hospitalizations and those that occurred before or after 2004 ( $\mathrm{N}=1,977 ; 23.5 \%)$, we also excluded those patients who died within 120 days after admission for MI $(\mathrm{N}=1,221 ; 14.5 \%)$. After further restricting the sample to those patients whose index hospitalization was $\geq 4$, but $\leq 30$ days and excluding admissions at non-acute care hospitals, we obtained a final study sample of 4,105 patients $(48.8 \%$ of the original hospitalization sample drawn). The mean age was 68.8 years (standard deviation, SD: \pm 13.2 ), and 2,442 (59.5\%) patients were men. Age differed considerably by gender: men (median: 66 years, interquartile range: 56-75) were substantially younger than women (median: 76 years, interquartile range: 67-82; $P<0.001)$. Overall, $654(15.9 \%)$ had their prescription copayments waived on the grounds of low income (Table 1). On average, they had been hospitalized for 6.7 $( \pm 14.7)$ days in the year prior to their MI and the mean length of stay for their index admission was $10.9( \pm 5.3)$ days. The proportions of selected prescription drugs used in the year prior to admission for MI are listed in detail in Table 1. 
Table 1 Characteristics of study population $(N=4,105)$

\begin{tabular}{lc}
\hline Variable & Count $(\%)$ or mean $( \pm \mathrm{SD})$ \\
\hline Age & $68.8( \pm 13.2)$ \\
$<50$ years & $402(9.8)$ \\
50-69 years & $1,515(36.9)$ \\
$70-89$ years & $1,225(29.8)$ \\
$\geq 90$ years & $963(23.5)$ \\
Male gender & $2,442(59.5)$ \\
Length of stay & $10.9( \pm 5.3)$ \\
Days of hospitalization in prior year & $6.7( \pm 14.7)$ \\
None & $2,500(60.9)$ \\
1-7 days & $595(14.5)$ \\
8-21 days & $612(14.9)$ \\
$\geq 21$ days & $398(9.7)$ \\
Copayment waived & $654(15.9 \%)$ \\
Previous medication use & \\
Alpha blocker & $243(5.9)$ \\
ACE-inhibitor or ARB & $1,853(45.1)$ \\
Beta-blocker & $1,454(35.4)$ \\
Calcium channel blocker & $809(19.7)$ \\
Other antihypertensive & $734(18.0)$ \\
Diuretic & $927(22.6)$ \\
Nitrate & $1,032(25.1)$ \\
Digitalis & $347(8.5)$ \\
Acetylsalicylic acid & $1,169(28.5)$ \\
Clopidogrel or Ticlopidine & $385(9.4)$ \\
Vitamin K-antagonist & $249(6.1)$ \\
Statin & $1,043(25.4)$ \\
Fibrate & $116(2.8)$ \\
Oral hypoglycemic & $620(15.1)$ \\
Insulin & $265(6.5)$ \\
Uric acid lowering drug & $559(13.6)$ \\
Pain medication & \\
Gastroprotective drug & \\
Asthma/COPD & \\
\hline
\end{tabular}

Secondary prevention after myocardial infarction

Within 120 days of their admission for MI, 3,037 (74.0\%; 95\% CI: 72.6-75.3\%) patients filled a prescription for a BB, 2,745 (66.9\%; 95\% CI: 65.5-68.3\%) for an ACE inhibitor or an ARB, and 2,736 (66.7\%; 95\% CI: 65.3$68.1 \%$ ) received a statin (Fig. 1). Indigent patients who were not required to pay a copayment received more ACE inhibitors or ARBs (74 vs. $65.5 \% ; P<0.001$ ), and slightly fewer statins $(63.2$ vs. $67.2 \% ; P=0.03)$, while the

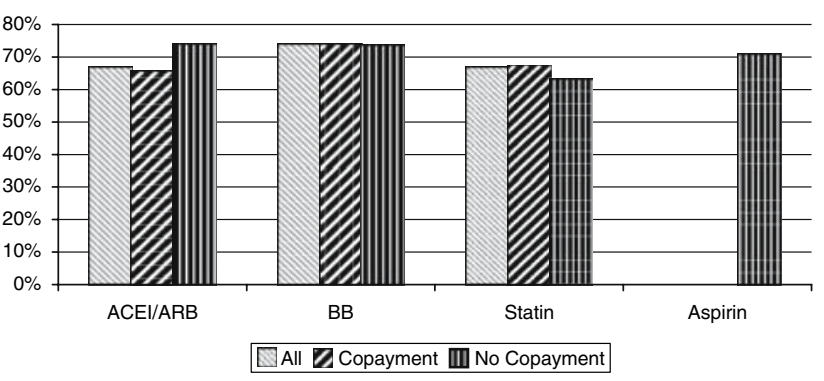

Fig. 1 Proportions of medication use after myocardial infarction

proportion of BB use was similar to patients without such a waiver $(P=0.86)$.

The distribution of number of distinct drug classes received in this population was as follows: 1,692 patients $(41.2 \%)$ received a $\mathrm{BB}$, statin, and an $\mathrm{ACE}$ inhibitor or $\mathrm{ARB}$, while 1,391 (33.9\%) received two of these drugs. Six hundred and sixty $(16.1 \%)$ patients received only one of the study drugs whereas $362(8.8 \%)$ patients received none of these medications for secondary prevention at all. This distribution did not differ between patients with vs. without copayment requirement $(P=0.33)$. The number of drugs received was slightly higher among men compared to women (2.1 vs. $2.0 ; P=0.02)$ and decreased with higher age $(\mathrm{P}<0.001)$. Among the 654 patients with waived copayment, $464(71 \%)$ filled a prescription for aspirin within 120 days of admission for MI.

Independent predictors of study medication use

Age was an independent predictor of recommended medication use after MI: compared to patients younger than 50 years, those between 70 and 89 years had $48 \%$ greater odds of receiving ACE inhibitors or ARBs (OR: 1.48), whereas the oldest patients ( $\geq 90$ years old) were least likely to receive these drugs (OR: 0.73; Table 2). Similarly, these oldest patients were also markedly less likely to receive BBs and statins (Tables 3 and 4). Number of days spent in the hospital in the year preceding the MI admission, a marker of preexisting comorbidity, was consistently and inversely associated with lower use of all these recommended medications (all $P$ for trend $<0.001$ ). Patients who had their copayments waived were more likely to fill a prescription for an ACE inhibitor or an ARB after discharge from MI than patients with copayment required (OR: 1.35 ; 95\% CI: 1.10-1.67), but BB or statin use did not differ between these groups. Angiotensin converting enzyme inhibitor or ARB use was further independently associated with previous calcium channel blocker use, use of an oral antidiabetic drug, and prior use of antipsychotic drugs (Table 2). Beta-receptor blockers were more likely to be used in patients who had used other antihypertensive 
Table 2 Independent determinants of ACE-inhibitor or ARB use

* $P$ for trend $<0.001$

medications prior to MI (Table 3). Lower use of BBs was observed in patients who had received diuretics, vitamin Kantagonist, insulin, antipsychotics, as well as in those patients who received inhaled medications for asthma or COPD (Table 3). Medications that were inversely associated with statin use were diuretics, digitalis, clopidogrel, vitamin K-antagonist, and antipsychotics (Table 4).

Naturally, prior use of a medication class was highly predictive of use of that class after MI in the full study population. Results from the analyses restricted to new users of each study drug were very similar to the full population analyses, albeit with wider confidence intervals (Tables 2-4). Analyses of independent predictors of number of recommended drugs received using linear or ordinal logistic regression confirmed what could be gleaned from the analyses of each drug class: older age, more hospital days in the previous year, indicator drugs for severe heart failure (digitalis, diuretics, vitamin K-antagonist), and antipsychotic use were all independently associated with fewer recommended medications received (results not shown). Gender, however, was not independently associated with number of medications received.

\section{Discussion}

In a large population-based study of patients who experienced an acute MI in Austria, we found that ambulatory use of several recommended medications after discharge was suboptimal. Within 120 days after their MI, only $74 \%$ patients received a BB, $67 \%$ a statin, and $67 \%$ filled a prescription for an ACE inhibitor or ARB. Only $41 \%$ of 
Table 3 Independent determinants of beta-blocker use

\begin{tabular}{|c|c|c|c|c|c|}
\hline \multirow[t]{2}{*}{ Variable } & & \multicolumn{2}{|c|}{ All patients $(N=4,105)$} & \multicolumn{2}{|c|}{ New users $(N=2,651)$} \\
\hline & & $\mathrm{OR}$ & $95 \% \mathrm{CI}$ & $\overline{\mathrm{OR}}$ & $95 \% \mathrm{CI}$ \\
\hline \multirow[t]{4}{*}{ Age } & $<50$ & - & Referent & - & Referent \\
\hline & $50-69$ & 1.25 & $0.98-1.60$ & 1.21 & $0.93-1.59$ \\
\hline & $70-89$ & 1.05 & $0.83-1.33$ & 1.14 & $0.87-1.47$ \\
\hline & $\geq 90$ & 0.62 & $0.51-0.76$ & 0.54 & $0.43-0.69$ \\
\hline \multicolumn{2}{|l|}{ Male gender } & 1.14 & $0.97-1.35$ & 1.19 & $0.98-1.43$ \\
\hline \multicolumn{2}{|l|}{ Length of stay } & 1.00 & $0.98-1.01$ & 1.00 & $0.98-1.01$ \\
\hline \multirow[t]{4}{*}{ Hospital days $*$} & 0 & - & Referent & - & Referent \\
\hline & $1-7$ & 0.92 & $0.74-1.15$ & 0.85 & $0.66-1.08$ \\
\hline & $8-21$ & 0.77 & $0.61-0.96$ & 0.78 & $0.60-1.02$ \\
\hline & $>21$ & 0.57 & $0.44-0.75$ & 0.61 & $0.43-0.84$ \\
\hline \multicolumn{2}{|c|}{ Copayment waived } & 1.09 & $0.89-1.35$ & 1.19 & $0.93-1.53$ \\
\hline \multicolumn{2}{|l|}{ Alpha-blocker } & 1.54 & $1.07-2.20$ & 1.73 & $1.12-2.67$ \\
\hline \multicolumn{2}{|c|}{ ACE-inhibitor or ARB } & 1.22 & $1.02-1.45$ & 1.16 & $0.94-1.41$ \\
\hline \multicolumn{2}{|l|}{ Beta-blocker } & 4.36 & $3.55-5.35$ & - & - \\
\hline \multicolumn{2}{|c|}{ Calcium channel-blocker } & 1.29 & $1.05-1.59$ & 1.49 & $1.16-1.90$ \\
\hline \multicolumn{2}{|c|}{ Other anti-hypertensive agents } & 0.83 & $0.68-1.01$ & 0.87 & $0.69-1.10$ \\
\hline \multicolumn{2}{|l|}{ Diuretic } & 0.80 & $0.65-0.98$ & 0.77 & $0.60-0.99$ \\
\hline \multicolumn{2}{|l|}{ Nitrate } & 1.03 & $0.84-1.26$ & 1.04 & $0.81-1.33$ \\
\hline \multicolumn{2}{|l|}{ Digitalis } & 0.79 & $0.60-1.04$ & 0.68 & $0.48-0.96$ \\
\hline \multicolumn{2}{|l|}{ Aspirin } & 0.96 & $0.79-1.16$ & 0.88 & $0.70-1.12$ \\
\hline \multicolumn{2}{|l|}{ Clopidogrel } & 0.79 & $0.59-1.07$ & 0.65 & $0.43-0.97$ \\
\hline \multicolumn{2}{|c|}{ Vitamin K-antagonist } & 0.67 & $0.49-0.93$ & 0.44 & $0.29-0.66$ \\
\hline \multicolumn{2}{|l|}{ Statin } & 0.94 & $0.76-1.16$ & 0.85 & $0.67-1.10$ \\
\hline \multicolumn{2}{|l|}{ Fibrate } & 1.14 & $0.70-1.86$ & 1.21 & $0.65-2.25$ \\
\hline \multicolumn{2}{|l|}{ Oral antidiabetic } & 1.06 & $0.85-1.32$ & 1.07 & $0.82-1.39$ \\
\hline \multicolumn{2}{|l|}{ Insulin } & 0.72 & $0.53-0.98$ & 0.78 & $0.52-1.16$ \\
\hline \multicolumn{2}{|l|}{ Asthma/COPD } & 0.67 & $0.55-0.83$ & 0.63 & $0.49-0.80$ \\
\hline \multicolumn{2}{|c|}{ Benzodiazepines/anxiolytics } & 1.33 & $1.04-1.71$ & 1.27 & $0.94-1.72$ \\
\hline \multicolumn{2}{|l|}{ Antidepressants } & 0.88 & $0.71-1.09$ & 0.96 & $0.74-1.24$ \\
\hline \multicolumn{2}{|l|}{ Antipsychotics } & 0.71 & $0.51-1.00$ & 0.74 & $0.50-1.09$ \\
\hline
\end{tabular}

in 9 (EUROASPIRE I), 15 (EUROASPIRE II), and 22 (EUROASPIRE III) countries, respectively; Austria did not participate in either of these. The most recent data available are from EUROASPIRE II, which covered the years 1999/ 2000 [28]. Medication use was assessed at admission, discharge (abstracted from charts), and at least 6 months (from patient interview) after the acute admission or procedure. While some variation was observed across countries, data specifically for after MI drug use was only reported in aggregate across countries. Approximately $74 \%$ of MI patients received a BB at discharge and $68 \%$ $>6$ months after the event; these proportions are similar to the $74 \%$ observed in our study. For ACEI, the proportions at discharge and $>6$ months after the event were 49 and $45 \%$, respectively, considerably lower than the $67 \%$ observed in Austria. It is unclear, however, whether ARB use was regarded equivalent to ACEIs and included in this 
Table 4 Independent determinants of statin use

\begin{tabular}{|c|c|c|c|c|c|}
\hline \multicolumn{2}{|l|}{ Variable } & \multicolumn{2}{|c|}{ All patients $(N=4,105)$} & \multicolumn{2}{|c|}{ New users $(N=3,062)$} \\
\hline & & OR & $95 \% \mathrm{CI}$ & OR & $95 \%$ CI \\
\hline \multirow[t]{4}{*}{ Age } & $<50$ & - & Referent & - & Referent \\
\hline & $50-69$ & 1.38 & $1.09-1.76$ & 1.40 & $1.09-1.81$ \\
\hline & $70-89$ & 1.08 & $0.86-1.36$ & 1.09 & $0.85-1.39$ \\
\hline & $\geq 90$ & 0.39 & $0.32-0.47$ & 0.37 & $0.30-0.46$ \\
\hline \multicolumn{2}{|l|}{ Male gender } & 1.10 & $0.94-1.29$ & 1.13 & $0.95-1.35$ \\
\hline \multicolumn{2}{|l|}{ Length of stay } & 0.98 & $0.97-0.99$ & 0.99 & $0.97-1.00$ \\
\hline \multirow[t]{4}{*}{ Hospital days* } & 0 & - & Referent & - & Referent \\
\hline & $1-7$ & 0.88 & $0.71-1.09$ & 0.82 & $0.66-1.04$ \\
\hline & $8-21$ & 0.68 & $0.55-0.85$ & 0.68 & $0.53-0.87$ \\
\hline & $>21$ & 0.48 & $0.37-0.63$ & 0.47 & $0.34-0.65$ \\
\hline \multicolumn{2}{|c|}{ Copayment waived } & 1.09 & $0.89-1.34$ & 1.07 & $0.85-1.34$ \\
\hline \multicolumn{2}{|l|}{ Alpha-blocker } & 0.89 & $0.65-1.22$ & 1.04 & $0.72-1.51$ \\
\hline \multicolumn{2}{|c|}{ ACE-inhibitor or ARB } & 0.98 & $0.82-1.16$ & 1.04 & $0.86-1.25$ \\
\hline \multicolumn{2}{|l|}{ Beta-blocker } & 1.08 & $0.91-1.29$ & 1.07 & $0.88-1.30$ \\
\hline \multicolumn{2}{|c|}{ Calcium channel-blocker } & 1.01 & $0.83-1.23$ & 0.98 & $0.79-1.23$ \\
\hline \multicolumn{2}{|c|}{ Other anti-hypertensive agents } & 0.97 & $0.80-1.18$ & 0.97 & $0.78-1.21$ \\
\hline \multicolumn{2}{|l|}{ Diuretic } & 0.82 & $0.67-1.00$ & 0.79 & $0.63-1.00$ \\
\hline \multicolumn{2}{|l|}{ Nitrate } & 0.94 & $0.77-1.14$ & 0.96 & $0.77-1.21$ \\
\hline \multicolumn{2}{|l|}{ Digitalis } & 0.60 & $0.46-0.80$ & 0.51 & $0.37-0.72$ \\
\hline \multicolumn{2}{|l|}{ Aspirin } & 0.85 & $0.71-1.03$ & 0.74 & $0.60-0.92$ \\
\hline \multicolumn{2}{|l|}{ Clopidogrel } & 0.70 & $0.51-0.94$ & 0.61 & $0.40-0.94$ \\
\hline \multicolumn{2}{|c|}{ Vitamin K-antagonist } & 0.62 & $0.45-0.85$ & 0.52 & $0.35-0.78$ \\
\hline \multicolumn{2}{|l|}{ Statin } & 6.39 & $5.03-8.11$ & - & - \\
\hline \multicolumn{2}{|l|}{ Fibrate } & 2.24 & $1.36-3.70$ & 2.31 & $1.35-3.97$ \\
\hline \multicolumn{2}{|l|}{ Oral antidiabetic } & 0.95 & $0.77-1.18$ & 0.98 & $0.77-1.26$ \\
\hline \multicolumn{2}{|l|}{ Insulin } & 0.76 & $0.56-1.04$ & 0.71 & $0.48-1.05$ \\
\hline \multicolumn{2}{|l|}{ Asthma/COPD } & 0.87 & $0.71-1.07$ & 0.84 & $0.66-1.06$ \\
\hline \multicolumn{2}{|c|}{ Benzodiazepines/anxiolytics } & 0.89 & $0.70-1.12$ & 0.94 & $0.72-1.22$ \\
\hline \multicolumn{2}{|l|}{ Antidepressants } & 1.13 & $0.91-1.40$ & 1.08 & $0.85-1.39$ \\
\hline \multicolumn{2}{|l|}{ Antipsychotics } & 0.48 & $0.34-0.68$ & 0.53 & $0.36-0.79$ \\
\hline
\end{tabular}

* $P$ for trend $<0.001$

of the study medications also needs to be taken into con-

quality measure in the EUROASPIRE study. Lipid-lowering drugs were prescribed to $42 \%$ of patients at discharge and used by $60 \%$ at $>6$ months after the event, compared to $67 \%$ in our study [28].

A comparison of these reports, however, needs to be conducted with caution. Considerable differences exist between these and other studies, especially in their population selection criteria, ascertainment of medication use, and the year(s) studied. Several studies, specifically from the United States and Canada, investigated medication use only in older patients ( $>65$ years) [33]. Results from elderly populations cannot be compared with findings from the general population, since age is a strong predictor of preventive medication use. Studies that measured medication use using discharge notes are likely to overestimate medication use, because patients may not have received a prescription or had chosen to not fill it. The increasing use sideration and, in this respect, older reports considerably vary with recent ones. To this point, Gislason et al. [24] studied MI patients in Denmark and found that the proportion of patients who received an ACE inhibitor increased from $25 \%$ in 1995 to $36 \%$ in 2002 . Similarly, use of $\mathrm{BB}$ increased from $38 \%$ to $68 \%$ during that time. This study differs from ours in that drug use was ascertained within 30 days following the discharge date from MI. While BB use is roughly similar to our findings, the use of ACE inhibitor was substantially lower in that Danish cohort. Statin or aspirin use was not part of that study, but a separate study using the same Danish database focused on this aspect of post MI care. In this report, statin use was ascertained within 6 months of discharge and increased from $13 \%$ in 1995 to $61 \%$ in 2002 [34]. This percentage is similar to the statin use of $67 \%$ in our Austrian sample, 
given that our data are slightly more recent; we did, however, use a shorter ascertainment window. Another report studied the use of preventive medications after $\mathrm{MI}$ in The Netherlands [26]. The authors confirmed a trend towards increased use of all drug classes from 1991 to 2000, with ACE inhibitor being dispensed to $44 \%$, BB to $76 \%$, and statins to $58 \%$ in the most recent study year (2000). Use of these medications was ascertained within 30 days after discharge, but patients were not required to survive for a minimum number of days after discharge to be eligible for study. Taking these study design differences into account, it appears that more patients received a BB after discharge in the Netherlands compared to Austria. Interestingly, neither the Dutch, nor the Danish study took ARB use into consideration as an established substitute for ACE inhibitors. Similarly, data from EUROASPIRE I and II confirms increasing use these preventive medications [29].

In the present study, we also identified several predictors of use for the study medications. In general, patients $\geq 90$ years of age were substantially less likely to receive these recommended medications than younger patients. Similar evidence for under-treatment among the elderly was also found in other countries [24]. This behavior may constitute general treatment bias against very old patients, or reflect that these patients may not live long enough to reap the benefits of long-term preventive interventions. Indeed, specific evidence on the efficacy and cost-effectiveness of the study medications in very old patients is lacking. In general, old patients were excluded from participation in virtually all efficacy trials on which current clinical practice recommendations are based. Only the PROspective Study of Pravastatin in the Elderly at Risk (PROSPER) trial has addressed this issue and specifically studied older individuals. PROSPER demonstrated that statins are efficacious in prevention of coronary events in older patients, but the participants in PROSPER were still "only" 70-82 years at enrollment [35]. Further, statin therapy has been shown to be cost-effective in 75-84 years old patients [36]. We found that those indigent patients who had their copayment waived had at least the same level of medication use compared to relatively more affluent patients who were responsible for the copayment portion of their prescription (€4.35), thus indicating that such a waiver successfully removed the economic barriers to filling these prescriptions. Of note, patients whose copayment was waived were more likely to be women and previous recipients of antipsychotic drugs, but otherwise similar to those who were required to pay a copayment (detailed results not shown).

The number of hospital days in the year prior to MI was a strong negative predictor of medication use for all classes. This might reflect greater comorbidity or frailty in these patients, which both have been associated with lower use of and persistence with preventive medications. Similarly, patients receiving antipsychotic drugs had a lower likelihood to receive the study medications, likely indicating treatment bias regarding the mentally diseased. Beta-blocker use was significantly lower among patients who received any drugs for inhalation that are indicated in asthma or COPD, a plausible pattern, which may reflect presence of a relative contraindication or intolerance by the patient. Indeed, among patients without previous use of such asthma or COPD drugs ( $\mathrm{N}=3,495)$, BB use after MI was $75.4 \%$ (rather than $74.0 \%$ in the overall population), an only slightly higher proportion with respect to the goal of appropriately treating all patients free from contraindications. Statins were less likely to be used in patients who had previously used diuretics, digitalis, or coumadin, possibly indicating congestive heart failure or atrial fibrillation and thus, worse prognosis.

In theory, and barring presence of any absolute contraindications, $100 \%$ of patients could receive each of these medications. Clearly, the actual proportion that could be attained in practice is lower than that, since some patients will have an absolute contraindication for any given drug. For ACEI/ARBs, this number would be very low, since the only absolute contraindication (other than pregnancy) is history of angioedema, whose incidence is below $1 \%$ among new ACEI users [37]. Beyond this, relative contraindications may exist such as hyperkalemia or advanced chronic kidney disease, but in most patients, at least a lowdose trial of an ACEI/ARB should be attempted with appropriate clinical and laboratory monitoring in place, possibly in combination with a loop diuretic. Similarly, for statins, practically every one should receive this treatment and absolute contraindications are either very rare (active liver disease) or not to be expected in this MI population (pregnancy, lactation). Thus, at least an attempt at using statins and ACEI/ARB in post-MI patients can be expected in probably $>95 \%$ of patients. The situation is slightly different with BBs, since more contraindications exist whose classification as absolute vs. relative are uncertain [38]. Cardiogenic shock, hypotension, and certain bradycardic arrhythmias untreated with a pacemaker certainly constitute absolute contraindications, whereas a treatment attempt in patients with stable obstructive lung disease should be conducted. From our dataset, it is difficult to ascertain most of these conditions, but when eliminating all patients who had received inhalative corticosteroids or beta mimetics, the percentage of BB users increased slightly to $75.4 \%$ from $74.0 \%$ in the overall population.

This report needs to be read with several limitations in mind. Aspirin was available at a price below the copayment for prescription medications. Thus, aspirin use may be underascertained in non-indigent patients. We were, 
however, able to assess aspirin use in those patients who had their copayment waived and found that $71 \%$ of patients received this drug. While we cannot be certain that medications received in the pharmacy were actually taken by these patients, our way of ascertaining medication use is superior to other methods. Compared to notes in medical charts, patients may not fill the prescriptions they were given. In surveys, patients may report what they perceive as being desirable rather than their actual behavior. Both methods, may lead to inaccurately optimistic estimates of medication use. In our study, comorbidities were not ascertained from diagnosis codes, but rather from typical medications that are given for several comorbidities. It has been shown that the information from diagnosis codes and from medication claims provides only marginally inferior confounding control in administrative datasets [39]. On a similar note, we were unable to ascertain reliable information on contraindications for the study drugs. Since most of these contraindications are relative rather than absolute contraindications [37, 38] this aspect may be of minor importance. While not fully population based, our data differ from other studies in that a wide range of hospitals and typical care settings were studied rather than single departments in predominantly academic medical centers. We consider our data generalizable to the population level, since three quarters of the Austrian population were included in the study, and the preponderance of patients omitted (1.2 Mio.; data from 2004) was excluded because they lived in the three Western provinces (Salzburg, Tyrol, Vorarlberg), whose sickness funds did not participate in our data collection effort. The remaining patients that we were unable to capture were members of very small corporate sickness funds, railroad and mining workers, as well as self-employed individuals; all those, however, received care at the same hospitals and by the same physicians as the enrolled patients. Finally, the analytical dataset did not contain linkable pseudoanonymized hospital identifiers. Thus, we were unable to study variations in treatment behavior across the provider level. It has been shown that provider preference can be a stronger determinant of treatment received than actual patient level indications [40].

In summary, we provide evidence for underuse of several recommended medications after MI as recently as 2004 in the Austrian healthcare system. Our observations are in line with findings from other European and North American healthcare systems, despite the differences in data collection and time period studied. Educational efforts need to be directed at both physicians and patients, and the implementation of quality indicators should be considered. Maximizing secondary prevention after MI is highly desirable from an individual patient and the societal perspective.
Acknowledgement Financial support was provided by the Hauptverband der Österreichischen Sozialversicherungsträger. The authors thank M. Asslaber and T. Burkhardt for their assistance in preparing this manuscript.

Open Access This article is distributed under the terms of the Creative Commons Attribution Noncommercial License which permits any noncommercial use, distribution, and reproduction in any medium, provided the original author(s) and source are credited.

\section{References}

1. Tunstall-Pedoe $\mathrm{H}$, Kuulasmaa $\mathrm{K}$, Mahonen $\mathrm{M}$, Tolonen $\mathrm{H}$, Ruokokoski E, Amouyel P. Contribution of trends in survival and coronary-event rates to changes in coronary heart disease mortality: 10-year results from 37 WHO MONICA project populations. Monitoring trends and determinants in cardiovascular disease. Lancet 1999;353:1547-57.

2. Rosamond WD, Chambless LE, Folsom AR, Cooper LS, Conwill DE, Clegg L, Wang CH, Heiss G. Trends in the incidence of myocardial infarction and in mortality due to coronary heart disease, 1987 to 1994. N Engl J Med 1998;339:861-7.

3. Burwen DR, Galusha DH, Lewis JM, Bedinger MR, Radford MJ, Krumholz HM, Foody JM. National and state trends in quality of care for acute myocardial infarction between 1994-1995 and 1998-1999: the medicare health care quality improvement program. Arch Intern Med 2003;163:1430-9.

4. Tunstall-Pedoe H, Vanuzzo D, Hobbs M, Mahonen M, Cepaitis Z, Kuulasmaa K, Keil U. Estimation of contribution of changes in coronary care to improving survival, event rates, and coronary heart disease mortality across the WHO MONICA Project populations. Lancet 2000;355:688-700.

5. Dickstein K, Kjekshus J. Effects of losartan and captopril on mortality and morbidity in high-risk patients after acute myocardial infarction: the OPTIMAAL randomised trial. Optimal trial in myocardial infarction with angiotensin II antagonist losartan. Lancet 2002;360:752-60.

6. Pfeffer MA, McMurray JJ, Velazquez EJ, Rouleau JL, Kober L, Maggioni AP, Solomon SD, Swedberg K, Van de Werf F, White H, Leimberger JD, Henis M, Edwards S, Zelenkofske S, Sellers MA, Califf RM. Valsartan in acute myocardial infarction trial I. Valsartan, captopril, or both in myocardial infarction complicated by heart failure, left ventricular dysfunction, or both. N Engl J Med 2003;349:1893-1906.

7. Winkelmayer WC, Fischer MA, Schneeweiss S, Levin R, Avorn J. Angiotensin inhibition after myocardial infarction: does drug class matter? J Gen Int Med 2006;21:1242-7.

8. Tsevat J, Kuntz KM, Orav EJ, Weinstein MC, Sacks FM, Goldman L. Cost-effectiveness of pravastatin therapy for survivors of myocardial infarction with average cholesterol levels. Am Heart J 2001;141:727-34.

9. Goldman L, Sia ST, Cook EF, Rutherford JD, Weinstein MC. Costs and effectiveness of routine therapy with long-term betaadrenergic antagonists after acute myocardial infarction. N Engl J Med 1988;319:152-7.

10. Goldman L, Weinstein MC, Goldman PA, Williams LW. Costeffectiveness of HMG-CoA reductase inhibition for primary and secondary prevention of coronary heart disease. JAMA 1991;265:1145-51.

11. Malik IS, Bhatia VK, Kooner JS. Cost effectiveness of ramipril treatment for cardiovascular risk reduction. Heart 2001;85:539-43.

12. Van de Werf F, Ardissino D, Betriu A, Cokkinos DV, Falk E, Fox KA, Julian D, Lengyel M, Neumann FJ, Ruzyllo W, Thygesen C, 
Underwood SR, Vahanian A, Verheugt FW, Wijns W. Management of acute myocardial infarction in patients presenting with ST-segment elevation. The task force on the management of acute myocardial infarction of the European Society of Cardiology. Eur Heart J 2003;24:28-66.

13. Giugliano RP, Braunwald E. 2004 ACC/AHA guideline for the management of patients with STEMI: the implications for clinicians. Nat Clin Pract Cardiovasc Med 2005;2:114-5.

14. Pollack CV Jr, Gibler WB. 2000 ACC/AHA guidelines for the management of patients with unstable angina and non-ST-segment elevation myocardial infarction: a practical summary for emergency physicians. Ann Emerg Med 2001;38:229-40.

15. O'Connor GT, Quinton HB, Traven ND, Ramunno LD, Dodds TA, Marciniak TA, Wennberg JE. Geographic variation in the treatment of acute myocardial infarction: the Cooperative Cardiovascular Project. JAMA 1999;281:627-33.

16. Bradley EH, Herrin J, Mattera JA, Holmboe ES, Wang Y, Frederick P, Roumanis SA, Radford MJ, Krumholz HM. Hospital-level performance improvement: beta-blocker use after acute myocardial infarction. Med Care 2004;42:591-9.

17. Krumholz HM, Chen J, Rathore SS, Wang Y, Radford MJ. Regional variation in the treatment and outcomes of myocardial infarction: investigating New England's advantage. Am Heart J 2003;146:242-9.

18. Epstein AM. Rolling down the runway: the challenges ahead for quality report cards. JAMA 1998;279:1691-6.

19. Lambie L, Mattke S. Selecting indicators for the quality of cardiac care at the health systems level in OECD countries. OECD Health Technical Papers No. 142004 available at http://www.oecd.org/;els/health/technicalpapers.

20. Tran CT, Lee DS, Flintoft VF, Higginson L, Grant FC, Tu JV, Cox J, Holder D, Jackevicius C, Pilote L, Tanser P, Thompson C, Tsoi E, Warnica W, Wielgosz A. CCORT/CCS quality indicators for acute myocardial infarction care. Can J Cardiol 2003;19:38-45.

21. Krumholz HM, Radford MJ, Wang Y, Chen J, Heiat A, Marciniak TA. National use and effectiveness of beta-blockers for the treatment of elderly patients after acute myocardial infarction: National Cooperative Cardiovascular Project. JAMA 1998;280:623-9.

22. Seddon ME, Ayanian JZ, Landrum MB, Cleary PD, Peterson EA, Gahart MT, McNeil BJ. Quality of ambulatory care after myocardial infarction among Medicare patients by type of insurance and region. Am J Med 2001;111:24-32.

23. Barron HV, Michaels AD, Maynard C, Every NR. Use of angiotensin-converting enzyme inhibitors at discharge in patients with acute myocardial infarction in the United States: data from the National Registry of Myocardial Infarction 2. J Am Coll Cardiol 1998;32:360-7.

24. Gislason GH, Abildstrom SZ, Rasmussen JN, Rasmussen S, Buch P, Gustafsson I, Friberg J, Gadsboll N, Kober L, Stender S, Madsen M, Torp-Pedersen C. Nationwide trends in the prescription of beta-blockers and angiotensin-converting enzyme inhibitors after myocardial infarction in Denmark, 1995-2002. Scand Cardiovasc J 2005;39:42-9.

25. Jullien G, Mosnier M, Danchin N. Évolution de la prescription de prévention secondaire chez les coronariens après revascularisation: enquête ANCOR [Evolution of secondary prevention medication prescriptions after myocardial revascularisation: the ANCOR survey]. Ann Cardiol Angeiol (Paris) 2005;54:184-9.

26. van der Elst ME, Bouvy ML, de Blaey CJ, de Boer A. Preventive drug use in patients with a history of nonfatal myocardial infarction during 12-year follow-up in The Netherlands: a retrospective analysis. Clin Ther 2005;27:1806-14.
27. EUROASPIRE A European Society of Cardiology survey of secondary prevention of coronary heart disease: principal results. EUROASPIRE Study Group. European action on secondary prevention through intervention to reduce events. Eur Heart $\mathbf{J}$ 1997; 18:1569-82.

28. Lifestyle and risk factor management and use of drug therapies in coronary patients from 15 countries; principal results from EUROASPIRE II Euro Heart Survey Programme. Eur Heart J 2001;22:554-72.

29. Clinical reality of coronary prevention guidelines: a comparison of EUROASPIRE I and II in nine countries. EUROASPIRE I and II Group. European action on secondary prevention by intervention to reduce events. Lancet 2001;357:995-1001.

30. Gouya G, Reichardt B, Ohrenberger G, Wolzt M. Survival of patients discharged after acute myocardial infarction and evidence-based drug therapy. Eur J Epidemiol 2007;22:145-9.

31. Bennett CL, Schwarz B, Marberger M. Health care in Austria. Universal access, national health insurance, and private health care. JAMA 1993;269:2789-94.

32. Kiyota Y, Schneeweiss S, Glynn RJ, Cannuscio CC, Avorn J, Solomon DH. Accuracy of Medicare claims-based diagnosis of acute myocardial infarction: estimating positive predictive value on the basis of review of hospital records. Am Heart $\mathbf{J}$ 2004;148:99-104

33. Pilote L, Beck CA, Karp I, Alter D, Austin P, Cox J, Humphries K, Jackevicius C, Richard H, Tu JV. Secondary prevention after acute myocardial infarction in four Canadian provinces, 19972000. Can J Cardiol 2004;20:61-7.

34. Rasmussen JN, Gislason GH, Abildstrom SZ, Rasmussen S, Gustafsson I, Buch P, Friberg J, Kober L, Torp-Pedersen C, Madsen M, Stender S. Statin use after acute myocardial infarction: a nationwide study in Denmark. Br J Clin Pharmacol 2005;60:150-8.

35. Shepherd J, Blauw GJ, Murphy MB, Bollen EL, Buckley BM, Cobbe SM, Ford I, Gaw A, Hyland M, Jukema JW, Kamper AM, Macfarlane PW, Meinders AE, Norrie J, Packard CJ, Perry IJ, Stott DJ, Sweeney BJ, Twomey C, Westendorp RG. Pravastatin in elderly individuals at risk of vascular disease (PROSPER): a randomised controlled trial. Lancet 2002;360:1623-30.

36. Ganz DA, Kuntz KM, Jacobson GA, Avorn J. Cost-effectiveness of 3-hydroxy-3-methylglutaryl coenzyme A reductase inhibitor therapy in older patients with myocardial infarction. Ann Intern Med 2000;132:780-7.

37. Lopez-Sendon J, Swedberg K, McMurray J, Tamargo J, Maggioni AP, Dargie H, Tendera M, Waagstein F, Kjekshus J, Lechat $\mathrm{P}$, Torp-Pedersen C. Expert consensus document on angiotensin converting enzyme inhibitors in cardiovascular disease. The task force on ACE-inhibitors of the European Society of Cardiology. Eur Heart J 2004a;25:1454-70.

38. Lopez-Sendon J, Swedberg K, McMurray J, Tamargo J, Maggioni AP, Dargie H, Tendera M, Waagstein F, Kjekshus J, Lechat $\mathrm{P}$, Torp-Pedersen C. Expert consensus document on beta-adrenergic receptor blockers. Eur Heart J 2004b;25:1341-62.

39. Schneeweiss S, Seeger JD, Maclure M, Wang PS, Avorn J, Glynn RJ. Performance of comorbidity scores to control for confounding in epidemiologic studies using claims data. Am J Epidemiol 2001;154:854-64.

40. Solomon DH, Schneeweiss S, Glynn RJ, Levin R, Avorn J. Determinants of selective cyclooxygenase- 2 inhibitor prescribing: are patient or physician characteristics more important? Am J Med 2003;115:715-20. 